127 COMPARISON OF TRANSVERSUS ABDOMINIS PLANE BLOCK AND LATERAL QUADRATUS LUMBORUM BLOCK IN PEDIATRIC PATIENTS; A DOUBLE BLIND RANDOMIZED CONTROLLED TRIAL

OP Zanbak Mutlu*, P Kendigelen, AC Tutuncu. Istanbul University-Cerrahpasa, Cerrahpasa Faculty of Medicine, Istanbul, Turkey

10.1136/rapm-2021-ESRA. 127

Background and Aims Undescended testicle is a common genitourinary pathology in pediatric population. Due to the complex innervation of the testicle and spermatic cord, analgesic management can be challenging in orchiopexy. We aimed to compare the effects of transversus abdominis plane (TAP) and lateral quadratus lumborum block (QLB) on peri-postoperative pain, analgesic use and patient satisfaction in unilateral orchiopexy.

Methods This prospective, double-blind, randomized, controlled trial was approved by IRB of Istanbul University-Cerrahpasa (2019-71381), registered to Clinicaltrials.gov (NCT03969316) and enrolled 90 pediatric patients aged 6 months to 12 years. Lateral QLB or TAP block were applied under ultrasonography before the surgery. Our primary outcomes were the remifentanyl consumption during the surgery and pain intensity within 24 hours postoperatively. Postoperative pain was evaluated with FLACC score in hospital, WongBaker score after discharge. Additional postoperative analgesic consumption and parent satisfaction were evaluated.

Results As a primary outcome, the number of patients who needed remifentanyl was found significantly higher in the TAP group $(\mathrm{p}<0,001)$. FLACC and Wong-Baker scores, except the

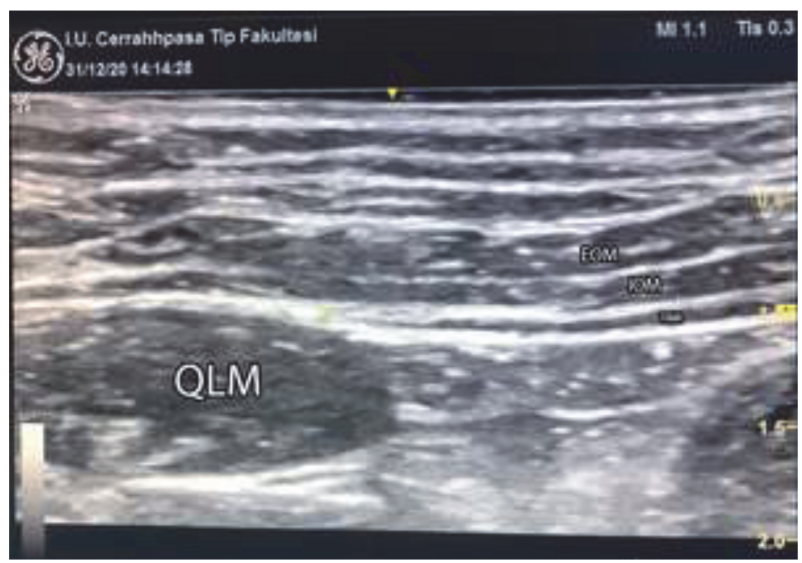

Abstract 127 Figure 1

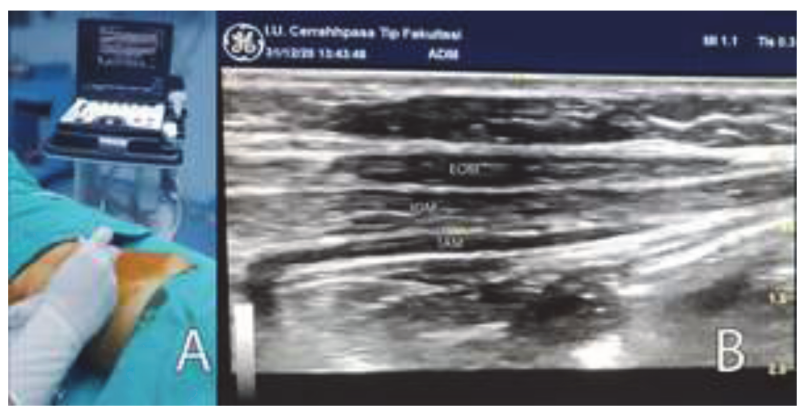

Abstract 127 Figure 2 postoperative first hour FLACC score, were detected significantly higher in TAP group $(\mathrm{p}<0,001)$. Additional analgesic agent consumption at the 10th, 20th minutes, 6th, 16th and 24th hours, especially after the 6th hour, were significantly higher in the TAP group. Parent satisfaction was significantly higher in the QLB group $(p<0.001)$.

Conclusions Preoperative lateral QLB is superior to TAP block in terms of peri-postoperative pain scores, additional analgesic requirement, patient satisfaction in orchiopexy, and it has been shown to be an appropriate option for the lower abdominal surgery in pediatric patients.

\section{SPINAL ANESTHESIA VERSUS GENERAL ANESTHESIA IN NEONATES UNDERGOING INFRAUMBILICAL SURGERIES REGARDING HEMODYNAMICS AND COMPLICATIONS}

M Hosny*, M Lamei, E El Taher, SA Al-Touny. Suez Canal University, Ismailia, Egypt

\subsection{6/rapm-2021-ESRA.128}

Background and Aims Neonatal anesthesia needs understanding of the rapidly changing physiology of the neonates, the pathology of the coexisting diseases, and the pharmacology of the medications used. The multisystem immaturity of this age generates developmental differences in the drug handling and response compared to older children ${ }^{(1,2)}$. Regional anesthesia in pediatrics may be beneficial ${ }^{(3)}$ to avoid airway manipulation and respiratory depression. It also improves intraoperative pain management or decreases the potential neurotoxic effects of intravenous or inhaled general anesthetics ${ }^{(4)}$. So, this study

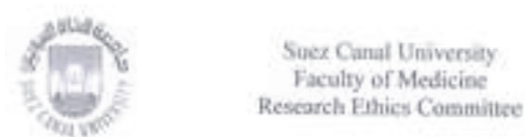

Date: 8/5/2019

Drit Mahmood Ifomy Ahined Ali Ahaned

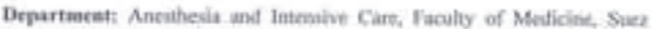
Canal thivernity. Imailia, Fopt.

Reterenev: Hesearch 3636 :

Thesis Thle: A Comparion beracen Spinal Anestheria and Genenal Asenthetia in Nosnutes Uoderyoing Infraumblical Surseries.

Dear Br,

Thank you for your leter in (30/4/2059) to ask fie the ethical clearanoe previoualy given foe the above mentiond thesis:

We are pleused to coafirm that the alowe mertioned thesis wan fir the partial folfillment of Masor digreve in Anestheria and fatemsive Care for

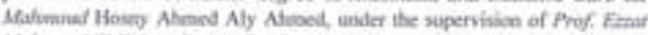

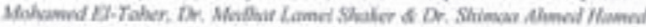
Alvourts:

The propenal of the above merntiobed theia was reviened by the full bourd Conmities at its metring on $01 / 1 / 2019)$ and the ethical elearaace nas given for that proponal.

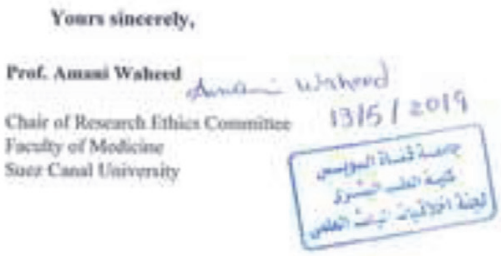

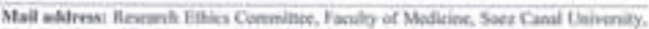

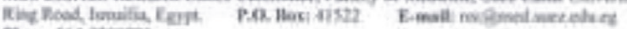

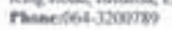

Abstract 128 Figure 1 